entirely dissected out of the more or less cone-shaped pit the axilla presents when these muscles are intact. In elderly persons, more particularly where the growth is slow, a complete operation like this may effect a cure, but in younger women, with a rapidly-growing tumour, the probability is the relief will be only temporary; as a rule the younger the patient the more rapid is the growth of a cancer. As regards dividing the clavicle, I camnot think there are any cases in which this is expedient; when the supraclavicular glands are infected the chance of cure is very small, and quick recurrence is the rule; the division and partial removal of the clavicle adds much to the subsequent inconvenience of the patient. The most favourable cases for operation are those in which the tumour is small and growing slowly, and no enlarged lymphatic glands can be detected, but an operation may be undertaken with a fair prospect of giving a considerable respite, if not a complete cure, where the disease is more advanced and the glands distinctly enlarged, if the operation is done carefully on the lines I have indicated, but there are certain cases in which the surgeon will be wise to leave the patient alone. I would mention the following conditions: where there are enlarged lymphatic glands that camnot be removed; where the whole of the diseased tissues cannot be removed (except under special conditions that I will mention presently); when the cancer is disseminated through the skin forming a sort of breastplate on the chest-cancer en cuirasse, as it is often called - for here the lymphatics of the skin are so infected that it is hopeless to think of a thorough removal; and where there is evidence of any secondary deposit in internal organs. Some would add where the disease is atrophying, as it sometimes does in old people, but I think where the patient's general condition is such as to warrant an operation, and when she is not averse to it herself, it is wisest to remove even an atrophying cancer, for there is always the possibility of its taking an active growth and getting to the inoperable stage; and, further, the operation is attended with practically no risk, and takes away what is to many a source of mental worry.

Before I conclude the treatment of cancer I should like to say that there are, in my opinion, two conditions in which an operation may be advised with the idea of giving relief, though a cure cannot be hoped for; one is where there is a rapidly-growing ulcerating sloughing tumour which is causing great pain, and by its weight and offensive odour, or both, is making the patient wretched; this, if removable, it may be wise to remove, notwithstanding that there is glandular enlargement, or even secondary deposits. If a tumour of this kind is nonremovable relief may be given by the application of what is called Fell's paste, the active ingredient of which is chloride of zinc; this often makes a dry eschar, checks the smell, and gradually diminishes the size of the tumour. The other is where in the earlier stage in a rapidly-growing tumour there is a good deal of oedema of the arm; clearing out the armpit may prevent that horribly painful and uncomfortable condition of oedematous arm that is sometimes met with in the later stages.

Sarcoma is rare and is met with as the round-celled and the spindle-celled variety; the former is a rapidly-growing infiltrating disease, sometimes it is encapsuled at first, but the capsule seems soon to give way. It occurs in comparatively young people, and presents itself as a roundish elastic swelling increasing rapidly in size, not as a rule attended by any puckering of the skin nor by any alteration in the normal condition of the nipple; it is frequently accompanied by enlargement of the glands and like growths of the kind in other places tends to infect the viscera, specially the liver. It has, as I remarked in speaking of cysts, a great tendency to cystic degeneration, and also to the formation of cysts by haemorrhage into its substance; the majority of so-called blood cysts are really sarcomata developing cysts in this way. I do not think that this disease can be mistaken for anything but the soft form of glandular cancer, and till removal a certain diagnosis cannot be made. The only treatment is early and free removal, but the prospect of non-recurrence is very slight. The spindle-celled variety is of slower growth, but otherwise it is clinically much like the other, though it rarely infects the glands or viscera. It should be treated by excision, and if it recurs it may be excised again, and this may be repeated as often as necessary; it generally remains local.

\section{Examination of the Breast.}

In conclusion, may I describe what appears to me to be the ideal way of examining a breast that is the subject of a swelling? From what I have said, you will appreciate the difficulty sometimes presented in coming to a correct diagnosis, and a practitioner should never be satisfied and should decline to commit himself to an opinion until he has made a complete local examination. The patient should preferably be seated in an ordinary chair, with her arms hanging down and the doctor seated opposite. If for any reason she has to be in bed, she should be placed flat on her back, with her head and shoulders slightly raised, and her arms lying beside her, the doctor standing at the left side of the bed; a shawl may be thrown loosely over the shoulders, otherwise the upper part of the body should be completely uncovered. Inspection is the first thing. The surgeon looks at the two breasts, noticing particularly any enlargement of either, or any puckering of the skin, also any alteration in the normal appearance of the nipple, and whether the two nipples are exactly opposite one another. He then places his hand flat on the affected breast, and carefully feels it all over. If he detects no tumour by manipulating in this way, he may be satisfied that there is not one. Should he feel a tumour, he will first notice whether it is tender or not, then satisfy himself whether it is circumscribed or diffuse. Then, by lightly moving his hand laterally to and fro, whether the skin is adherent to it; then whether it is adherent to the pectoral muscle; and to ascertain this it is well for an assistant to support the arm and alternately relax and tighten the pectoral. The next thing is to examine the tumour with the two forefingers, ascertain its relative hardness and decide whether there is fluctuation or not, and, lastly, the axilla and supraclavicular region should be examined for enlarged glands. In doing this the arm should be supported, and the muscles forming the axilla relaxed, and two fingers of the right hand employed. The whole axilla should be felt, more particularly the outer part, as there are usually glands found enlarged along the line of the axillary vein, if there are any. The forefinger should carefully feel the hollow above the clavicle and the back edge of the sterno-mastoid muscle. It is desirable also to examine the axilla of the unaffected side, as some people have enlarged glands from another cause, and the enlargement on the affected side may not be due to the condition of the breast.

\section{ENUCLEATION OF THE PROSTATE FOR HAEMORRHAGE.}

By Sir WILLIAM THOMSON, C.B.,

SURGEON RICHMOND HOSPITAL, DUBLIN ; HONORARY SURGEON TO HIS MAJESTY THE KING.

I sELEct this case from a further series of suprapubic operations because it presents certain uncommon features in its history and its course which must be of interest to many who are engaged in what is called urinary surgery.

A gentleman, aged about 57, was in 1901 suddenly the subject of haemorrhage from the bladder. He had not previously suffered in any way to account for it, and he was naturally startled to find that he had passed on this occasion what to him appeared to be pure blood. The haemorrhage only occurred after violent exercise or after riding or driving over rough roads. In 1902 in London he saw a physician, who suggested that he had stone in the kidney, and in consultation with another physician it was agreed that the patient should go to Contrexéville, and this he did. The bleeding, however, continued after smart exercise as before, and only then; and the patient consulted another physician in London, who thought there might be a stone, but he also feared there might be a villous growth in the bladder. A skiagraph was taken of the kidneys and of the bladder by a very skilled skiagraphist, but there was no visible evidence of calculus.

In 1903 the gentleman first consulted me and gave me the history of his case. He complained that exercise was usually followed by the presence of blood in the urine, usually just sufficient to stain the fluid. He had no pain of any kind in the loins, in the urethra, or in the bladder. 
He had no difficulty in micturition, and could hold water for five hours during the day. He slept well, and on awaking at five or six o'clock, as was his habit, he passed water in a good stream. An examination of the rectum showed that the prostate was considerably enlarged. It was soft and smooth, and presented to the touch no character of malignancy.

The urine was frequently examined by Dr. Earl, and its general character was: Specific gravity ranging from 1018 to 1025 , acid reaction, no albumen, urea from 8 to $10 \frac{1}{2} \mathrm{gr}$. per oz., with a deposit of urates and some oxalate of lime crystals, epithelial cells from the urinary passages, and sometimes a few red corpuscles.

Skiagraphs of the kidneys were taken by Dr. Haughton, but nothing could be discerned to indicate the presence of stone. Later on I recommended the patient to see Mr. Henry Morris in London, and he agreed with me that although the character of the urine indicated stone somewhere, it would be unwise to make any exploratory operation in the circumstances. He could find no sign of mischief about the renal regions.

From this on to May last year the patient was intermittently under my care, never at any time complaining of anything save the occasional appearance of blood in the urine. I pointed out to lim that in my opinion he was not suffering from villous tumour as had been thought possible, because it would probably have by this time produced symptoms which would be marked and severe. As to the kidneys, there was no evidence of stone in the repeated skiagraphs; and, moreover, if the bleeding depended upon a calculus in either, the mobility which produced haemorrhage would also produce pain. This brought the diagnosis down to stone in the bladder or to haemorrhage from the prostate. But there was no sym ptom of stone there save the occasional appearance of blood, which of course was not by itself conclusive; and as, for reasons special and personal, I did not wish to introduce a sound, I had only the condition of the urine to guide me. My opinion was that there might be a stone or stones lying in a post-prostatic pouch, and prevented by this from rolling to the neck of the bladder when the urine was discharged, and so producing pain. I pointed out that if it should become necessary to remove the prostate, any stones could be dealt with at the same time, but that there was no necessity to operate upon the gland in its then condition. There had never been any retention of urine, or need at any time to pass a catheter, but the need of micturition had become more frequent.

This was still the condition of affairs in May, 1905. I saw the patient on May 12th. In June he started on a holiday. In London a friend suggested that he should see a surgeon, and he did see one. The bladder was examined with a sound, but no stones could be found, but the prostate was found to be much enlarged. On examination by cystoscope was suggested; but the gentleman started for Contrexéville, and arrived there suffering for the first time from retention of urine. His physician had to introduce a catheter. He told the patient he should not have come, treated him for a few days, and sent him back. In London he was found to be suffering from cystitis, and was advised to return to Dublin at once, and accordingly he arrived on June 22nd, when I saw him. He was now vely ill, with the usual symptoms. There was no blood, but the urine was alkaline, and very fetid; stringy mucus and pus were abundant. Careful washing out through a rubber catheter and other remedies resulted in acid urine for a few days, and then there was a relapse. I had to leave town on July 8th, and on the evening of that day he had a sudden and severe haemorrhage from the bladder. Sir Charles Ball was sent for in my absence. The bleeding continued at intervals, and Sir C. Ball saw him with me on July 11th. Various remedies were tried but without any marked result. The blood was bright, and came away in large quantities, and we were agreed that it came from the prostate. I had the advantage of seeing the patient with Sir C. Ball and Sir Francis Cruise several times, and we agreed that I should open the bladder above the pubis and enucleate the prostate. On July 15th the bleeding had somewhat decreased, and the patient was removed in an ambulance to a priva'e hospital. Next morning, the bleeding not having ceased, we determined to operate, and this I did, Sir C. Ball, Sir Francis Cruise, Dr. J. O'Carroll, and Dr. Peacocke being present.
The bladder was opened in the usual way, and stones were detected in a post-prostatic pouch; they numbered 32. They were smooth and rounded, and about fourteen were of the size of large peas. They were subsequently found to be composed of oxalate of lime. The prostate was soft, and projected far into the bladder, the right lobe being the longer. The adhesions were very intimate, and it required a great deal of force to break these down. The gland weighed $2 \mathrm{oz}$.

There was a good deal of bleeding during the removal, but this was controlled by hot douching, and when the operation was ended haemorrhage had entirely ceased ; it never recurred in any form. Considerable shock followed, but the patient made excellent progress, and was able to sit up on the fourteenth day. In four weeks he. returned to his own residence. In the fifth week he had a sudden attack of rigors and vomiting, followed by profuse sweating. For a day he was delirious, and in a urinary case the symptoms were very alarming. But Sir Francis Cruise and I soon came to concur in the patient's own view-that he was suffering from an outburst of malarial fever, and he had quite recovered in three days.

There was some intermittent leakage from a pinhole opening, but it entirely ceased in September. He passe urine by the urethra in a full stream without the least irritation or pain, and can retain water for five or six hours without uneasiness. In October it was necessary to remove a painful portion of the cicatrix, which was the last to heal, and which covered a few drops of pus. From this the patient quickly recovered.

The case was one of difficulty, and in the end of great anxiety. The only signs present were occasional slight quantities of blood and an enlarged prostate. But of stone in the kidney or bladder the $x$ rays gave no indication, and the only hint was derived from the presence of oxalate of lime crystals in the urine. There had never been any symptom of renal colic, or tenderness over the kidneys, nor was there any symptom or sign of stone in the bladder save a little blood which now and again appeared after exercise. But having found an enlarged prostate I could not exclude the possibility of there being calculi in the post-prostatic pouch.

I have mentioned that the bladder was sounded in London in June and that no stones were found. Had I, however, been aware of the intention to sound I should have given reasons for postponing that procedure in the special case; but of the proceedings in London I knew nothing, as no communication was made to me.

The haemorrhage, which broke out without any warning, was, with one exception, the most severe I have ever met with in like cases. It was obvious that although it had somewhat diminished we could not allow it to go on, and the only course was to deal with it directly by operation. A subsequent examination of the gland showed three patches of marked extravasation beneath the surface of the left lobe, and I have no doubt the liaemorrhage had taken place there.

The removal of the enlarged prostate for existing alarming haemorrhage has not been before advocated or deliberately practised-at least, so far as I am aware. I do not doubt that when bleeding cannot be otherwise controlled it is the proper treatment. The surgeon is thus enabled. to reach the source of the flow at once and to remove it.

\section{LIBRARY OF THE BRITISH MEDICAL} ASSOCIATION.

Members are reminded that the Library and Writing Rooms of the Association are fitted up for the accommodation of the members in commodious apartments, at the office of the Association, 429, Strand. The rooms are open from 10 a.m. to 5 p.m., except on Saturdays, when it closes. at 2 p.m. Members can have their letters addressed to them at the office.

AT a meeting of the Neurological Society of the United Kingdom, to be held at the rooms of the Medical Society of London on Thursday next, at 8.30 p.m., Mr. W. Bateson, F.R.S., will read a paper on Mendelian heredity and its application to man. 